\title{
EUTOMIA
}

Revista de Literatura e Linguística

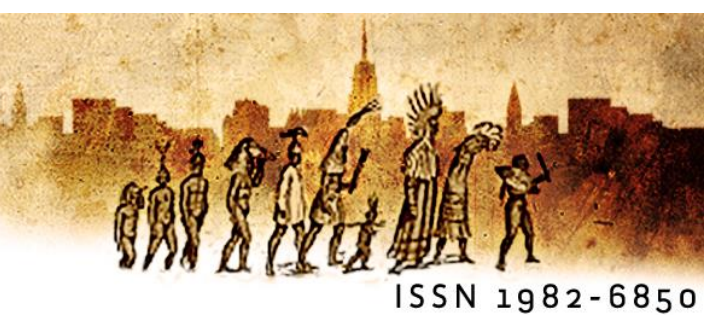

\section{O desenvolvimento profissional de uma professora- pesquisadora do Instituto Federal de São Paulo: uma ressignificação da vivência a partir do diálogo e da narrativa}

\section{The professional development of a teacher-researcher at the Federal Institute of São Paulo: a resignification of the experience from dialogue and narrative}

Resumo: O presente artigo, resultado de uma pesquisa em andamento de doutorado, tem por objetivo analisar, a partir da narrativa de uma professora que atua no Instituto Federal de Educação, Ciência e Tecnologia de São Paulo, como esta tem se constituído como professora, bem como compreender qual a importância do outro nesse processo de significação do papel docente e do contexto de formação. Para essa investigação, pautamo-nos nas considerações da perspectiva histórico-cultural e enunciativa, bem como nas considerações de Paulo Freire. Nossas análises revelam que, ao narrar suas vivências, o sujeito as ressignifica e esse processo contribui para uma reflexão sobre sua trajetória e desenvolvimento profissional. Todavia, isso só se torna possivel mediante as relações dialógicas que medeiam a produção dessa narrativa.

Palavras-chave: narrativa; ressignificação; desenvolvimento profissional; relações dialógicas.

\begin{abstract}
This article, the result of an ongoing doctoral research, aims to analyze, from the narrative of a teacher who works at the Federal Institute of Education, Science and Technology of São Paulo, as this has been constituted as a teacher, as well as to understand the importance of the other in this process of meaning of the teaching role and the context of training. For this investigation, we are based on the considerations of the historical-cultural and enunciative perspective, as well as on the considerations of Paulo Freire. Our analyses reveal that, when narrating their experiences, the subject (re)signifies them and this process contributes to a reflection on their trajectory and professional
\end{abstract}


development. However, this is only possible through the dialogical relationships that mediate the production of this narrative.

Keywords: narrative; resignification; professional development; dialogical relations.

\section{Considerações iniciais}

O trabalho investigativo, a partir de narrativas docentes, tem crescido bastante nos últimos anos, possibilitando compreender como os professores vão se constituindo a partir de suas experiências de vida mediadas pelo outro, bem como ressignificam tais experiências a partir do ato de narrar. Nesse sentido, o presente artigo, resultado de uma pesquisa em andamento de doutorado, tem por objetivo analisar, a partir da narrativa de uma professora que atua no Instituto Federal de Educação, Ciência e Tecnologia de São Paulo, como esta tem se constituído como professora, bem como compreender qual a importância do outro nesse processo de significação do papel docente e contexto de formação.

Tais reflexões são importantes, uma vez que, segundo Hernández (2011), o percurso investigativo das histórias de vida, desde os princípios da década de 1970, buscou questionar as visões tecnocráticas e positivistas sobre o comportamento e a educação. Dessa forma, surgiu uma "revalorización de la importancia del significado y la interpretación en los procesos, actividades, experiencias y comportamientos humanos y el redescubrimiento del valor de la subjetividad"1" (HERNÁNDEZ, 2011, p. 14).

Tomamos, nesse sentido, a narrativa como objeto de análise compreendendo-a como um meio/modo de produção de conhecimento, em que emergem as marcas das vivências e vozes do enunciador e dos outros. Fundamentamo-nos, para essa discussão, nas perspectivas histórico-cultural de Lev Vygotsky, enunciativo-discursiva de Mikhail Bakhtin, bem como nas proposições de Paulo Freire para discorrer sobre a relação da narrativa com a formação e desenvolvimento profissional.

Cabe ressaltar desde já que entendemos a formação e o desenvolvimento profissional como um processo dinâmico entre o singular e o coletivo, isto é, que é potencializado pelo outro. É, nesse sentido, que a narrativa sobre a trajetória pessoal e profissional pode ser considerada um texto dialogicamente marcado, quando se pensa na

\footnotetext{
1 "Revalorização da importância do significado e interpretação nos processos, atividades, experiências e comportamentos humanos e a redescoberta do valor da subjetividade" (HERNÁNDEZ, 2011, p. 14 - tradução nossa).
}

Eutomia, Recife, 27(1): 143-163, Out. 2020 
importância do outro no processo de constituição, seja este outro um familiar, um colega de trabalho ou um aluno. É na narrativa que podemos, a partir dos signos, observar a emergência das ressignificações das vivências, as possibilidades do devir, regidas pelo inacabamento, o poder da alteridade, a postura ética e integrada aos valores cultivados ao longo da vida, que se formam numa mescla entre o vivido, o que se está vivendo e sua projeção para o futuro.

Assim, organizamos esse artigo da seguinte forma: primeiramente, apresentamos alguns conceitos teóricos que nos norteiam a olhar para a trajetória e desenvolvimento profissional da professora. Em seguida, apresentamos os procedimentos metodológicos que utilizamos para a produção dos dados. Posteriormente, trazemos nossas análises acerca da narrativa da professora e, por fim, nossas considerações finais.

\title{
1. Constituição docente e desenvolvimento profissional: a narrativa como possibilidade de ressignificação das vivências a partir da interação com os outros.
}

Trabalhar com narrativas é reconhecer que cada história é única e singular, todavia, também a síntese de uma prática social que se dá em um processo inteiramente dialético. Narrar é uma forma de ressignificar as vivências. E a vivência é aqui entendida como

\begin{abstract}
uma unidade na qual, por um lado, de modo indivisível, o meio, aquilo que se vivencia está representado - a vivência sempre se liga àquilo que está localizado fora da pessoa - e, por outro lado, está representado como eu vivencio isso, ou seja, todas as particularidades da personalidade e todas as particularidades do meio são apresentadas na vivência, tanto aquilo que é retirado do meio, todos os elementos que possuem relação com dada personalidade, como aquilo que é retirado da personalidade, todos os traços de seu caráter, traços constitutivos que possuem relação com dado acontecimento. Dessa forma, na vivência, nós sempre lidamos com a união indivisível das particularidades da situação representada na vivência (VIGOTSKI, 2010, p. 686).
\end{abstract}

Nesse sentido, entendemos a formação do professor como aquela que se pauta nas suas práticas, nas suas necessidades e, no trabalho realizado com e para o outro. A formação na perspectiva do desenvolvimento profissional envolve, portanto, um processo dinâmico entre o singular e o coletivo, potencializado pela mediação do outro. Isso significa que quando o professor vivencia uma determinada situação, seja tanto no âmbito pessoal 
quanto profissional, interagindo com os outros, seja discutindo, discordando, concordando, expondo as dificuldades, significando e ressignificando suas vivências, ele se desenvolve, produz e adquire saberes e novas aprendizagens. A significação que emerge a partir das narrativas é entendida aqui como produção humana de signos e sentidos que vão sendo construídos nas interações verbais, isto é, nas práticas sociais concretas das relações humanas.

Todo sujeito aprende com o outro e isso se dá num movimento de (trans)formação, o que faz da vida, segundo Bakhtin (2011), ser dialógica por natureza. Diante disso, mostrase importante assumir que o dialogismo não se apresenta meramente como uma categoria científica, pois trata-se de uma filosofia que abrange o próprio ato de existir. Ademais, podemos preconizar que o dialogismo figura como uma filosofia do diálogo.

Como tal, temos o diálogo como indício de que o eu não existe individualmente, pois carece de um outro para estabelecer tal diálogo. A palavra, sendo dialógica, estabelece tal relação entre o eu e o tu. Assim, o diálogo figura como a participação do homem com o existir, que se manifesta por meio de respostas direcionadas a esse outro.

Como o princípio dialógico se mostra contumaz na esfera da atividade humana, cabe traçarmos um percurso cuidadoso ao abordá-lo, uma vez que permeia toda a teoria do filósofo russo e de seu Círculo. Para tal, devemos demonstrar que o conceito da linguagem percebe

a língua em sua integridade concreta e viva e não a língua como objeto específico da linguística, obtido por meio de uma abstração absolutamente necessária de alguns aspectos da vida concreta do discurso. Mas são justamente esses aspectos, abstraídos pela linguística, os que têm importância primordial para nossos fins. (BAKHTIN, 2013, p. 207)

Doravante, a partir da leitura do trecho, percebemos que, para Bakhtin (2013), a linguagem é fruto de uma ação viva, e não estanque como sugerido por um sistema de formas, ou meramente estável e imutável, abstraído das relações sociais. Temos aqui uma importante acepção: a de que o ato de fala se revela de natureza social. Firmamos, como também asseverou Volóchinov (2018), que toda enunciação não se percebe como um produto individual do falante; por isso pressupõe a interação entre indivíduos socialmente organizados, sendo que tal palavra sempre é dirigida a outrem. A palavra, desta forma, passa a ser orientada em função deste outro. 
Assim, sendo a língua uma atividade essencialmente social, firmada na comunicação entre os falantes, podemos compreender o enunciado como um elemento dessa interação comunicativa, com irrestrita associação com a vida. O enunciado se direciona ao ato concreto do uso da linguagem, sendo a enunciação um reflexo da natureza sócio-histórica, estando ligada a enunciações anteriores e posteriores, relacionando-se ao tempo e ao espaço da realização do discurso, estando ligada ao produto das interações entre os falantes. A enunciação, portanto, refere-se ao momento da interlocução, ou seja, envolve tanto o contexto social do qual participa, quanto ao conteúdo ideológico. Mesmo sendo um processo individual que repercute a partir do psiquismo do falante, a enunciação é um fenômeno de natureza social. Segundo Bakhtin (2016), "cada campo de utilização da língua elabora seus tipos relativamente estáveis de enunciados, os quais denominamos gêneros do discurso" (BAKHTIN, 2016, p. 12).

O fato de o sujeito ter de escolher por um determinado gênero do discurso ao enunciar, demonstra o quão ele é social, uma vez que representa o campo de comunicação no qual é produzido. Reiteramos que todo ato discursivo possui sua condição de irrepetibilidade, ou seja, é único e singular, contudo, traz consigo elementos que refletem e refratam o campo social no qual foi erigido.

Ademais, existe outro fenômeno essencial na produção de um enunciado concreto, que se caracteriza pela "possibilidade de seu direcionamento a alguém, de seu endereçamento" (BAKHTIN, 2016, p. 62). Isto significa que, assim que o ouvinte compreender o significado do discurso, acaba por ocupar uma posição responsiva-ativa, ou seja, assume uma posição de concordância ou discordância (que pode ser total ou parcial), além de buscar completar os seus sentidos, ou mesmo usá-los. Tal fenômeno, segundo Bakhtin (2016), dá-se a partir da primeira palavra do falante, perdurando por todo o discurso, o que caracteriza o enunciado como um processo ativo, o qual exige a resposta do interlocutor.

Nesse processo de interação através do diálogo, podemos salientar que um enunciado não nasce à deriva, surgindo do nada, ele próprio é uma resposta a enunciados anteriores, o qual assume um posicionamento diante de enunciados pertencentes ao mesmo tema. Com isso, há uma renovação dos sentidos possíveis desses enunciados, 
promulgando um novo giro de entendimentos, pois "cada enunciado é um elo na corrente complexamente organizada de outros enunciados" (BAKHTIN, 2016, p. 26).

Toda palavra serve de expressão ao "um" em relação ao "outro". Na palavra, eu dou forma a mim mesmo do ponto de vista do outro e, por fim, da perspectiva da minha coletividade. A palavra é uma ponte que liga o eu ao outro. Ela apoia uma das extremidades em mim e a outra no interlocutor. A palavra é o território comum entre o falante e o interlocutor (VOLÓCHINOV, 2018, p. 205).

A palavra, metaforizada como ponte, funciona como um elo condutor que permite as relações sociais entre os sujeitos, construindo uma rede de comunicação entre eles. Sob esse prisma, a linguagem para Bakhtin está embasada nas relações dialógicas e sociais desses sujeitos que interagem ininterruptamente, servindo como fundamento teórico para a análise da história de vida que apresentaremos, percebendo que a linguagem é, essencialmente, fruto de uma interação verbal e responsável pela constituição dos sujeitos.

Além disso, cabe frisar que, segundo Bakhtin (2017), o eu é constituído a partir do outro. Sendo assim, para reconhecer-se como si próprio, o sujeito deve perceber o outro como um não-eu, o que objetiva uma eventicidade única do Ser, orquestrada por uma temporalidade histórica. Ao lidar com o outro, numa cadeia exotópica de troca de significados, somente dentro de uma arquitetônica estética podemos colocar o outro em um processo de valoração.

Ao manter o contato com o outro, desenvolve-se o próprio ser, num construto que se pode chamar de movimento exotópico, que seria a capacidade de ver-se a si mesmo fora de si. Além disso, consiste na construção de uma interpretação de si a partir do olhar do outro; o que falta ao eu encontra-se refletido nesse outro que nos movimenta nesse diálogo infinito. Assim, "não sou eu que olho o mundo de dentro com os meus próprios olhos, mas sou eu que olho a mim mesmo com os olhos do mundo, com os olhos alheios; eu sou possuído por um outro." (BAKHTIN, 2019, p. 51, grifo do autor).

Nesse sentido, reconhecem-se as marcas de uma postura dialógica diante da vida, no sentido de auferir ao outro a possibilidade de angariar valores às suas ações cotidianas, firmando um posicionamento mediante tais escolhas, que se define a partir de uma postura responsiva e responsável. 
A vida é evento e a vida só pode ser compreendida na responsabilidade concreta do sujeito. Essa responsabilidade (ou seja, o ato responsável) é baseado na singularidade do não-álibi da existência. Assim, a alteridade leva o sujeito a uma responsabilidade éticodiscursiva, isto é, em direção ao ato ético.

A alteridade conduz os sujeitos, reproduzindo sua dimensionalidade em suas ações e reações, palavras e contra palavras, numa escala muito ampla, sempre firmada no social. Por isso, Bakhtin (2011) mostra que o sujeito está impregnado de palavras dos outros. Ao construir seus diálogos, o sujeito carrega a voz de outros, que reestrutura e modifica após a apropriação.

Com isso, ao assumir tal questão, no que tange ao desenvolvimento profissional de um professor (ou professora), destaca-se um compromisso responsivo-ativo inerente ao educador, pois este se constitui como um ser pedagógico que, a partir da identidade firmada na alteridade, reproduz as palavras daqueles que melhor personificaram seu caminho até a constituição dessa identidade peculiar, a de ser professor. Retomamos nesse sentido, as proposições de Vigotski (1995) sobre a natureza social do desenvolvimento humano. Para o autor, o conhecimento tem origem nas relações sociais e é produzido na dinâmica intersubjetiva, isto é, pressupõe uma relação mediada entre sujeitos e objeto de conhecimento em condições concretas. Isso pressupõe que

as características tipicamente humanas não estão presentes desde o nascimento do indivíduo, nem são mero resultado das pressões do meio externo. Elas resultam da dialética do homem e seu meio cultural. Ao mesmo tempo em que o ser humano tranforma o seu meio para atender suas necessidades básicas, transforma-se a si mesmo (REGO, 1995, p. 41).

Ao considerarmos esse movimento dialético, não estático e imutável do desenvolvimento, precisamos levar em consideração de que para Vigotski (1995) é a cultura que constitui a natureza humana. Além disso, para o autor, a relação do homem com o mundo não ocorre de forma direta, mas mediada por signos e instrumentos que são construídos historicamente. Segundo ele,

A função do instrumento é servir como um condutor da influência humana sobre o objeto da atividade; ele é orientado externamente; deve necessariamente levar a mudanças nos objetos. Constitui um meio pelo qual a atividade externa é dirigida para o controle e domínio da natureza. $\mathrm{O}$

Eutomia, Recife, 27(1): 143-163, Out. 2020 
signo, por outro lado, não modifica em nada a objeto da operação psicológica. Constitui um meio da atividade interna dirigido para o controle do próprio indivíduo: o signo é orientado internamente (VIGOTSKI, 1995, p. 55).

A mediação dos instrumentos e signos é o cerne das proposições do autor, uma vez que é a partir deles que os processos psíquicos superiores são fornecidos pela cultura. Dentre esses signos, a linguagem torna-se, para esse autor, o signo de excelência uma vez que sua natureza não pode ser atribuída a um sujeito considerado isoladamente, mas a um ser social. Todo sujeito vai se constituindo à medida que interage com o outro. São os signos, a palavra e o outro que impulsionam o desenvolvimento humano, uma vez que a significação só acontece no processo de interação entre o eu e o outro.

E se a linguagem é condição sine qua non para o desenvolvimento, compreendemos a narrativa como um gênero discursivo em que emergem diferentes significações. Através dela é possível analisar não apenas a trajetória pessoal, mas também o desenvolvimento profissional, pois é possível identificar as marcas do agir de forma ética, dialógica que leva à alteridade, à construção de uma identidade professoral firmada em seu compromisso com a aprendizagem, com o que existe de mais humano: a capacidade de humanizar o outro.

Nesse processo de enriquecimento sugerido por Bakhtin, podemos perceber a ação ética docente, uma vez que, munido de um intercâmbio de sua própria realidade, o professor engajado percebe as mesmas dificuldades que teve na persona do aluno, ajudando-o, sobremaneira, a transpor tais problemas como uma espécie de projeção, pois através do olhar do outro identifico minhas próprias vicissitudes.

Por isso, para compreender a constituição do sujeito professor e discorrer sobre o desenvolvimento profissional, é necessário olharmos para a percepção da vivência humana como uma produção de signos e de um inacabamento profundo. O devir, portanto, revela o caráter inacabado das relações humanas, demonstrando que o sujeito se encontra em relação permanente com o mundo, transformando-o. Sendo causa e efeito de suas transformações histórico-culturais, se mostra em perpétua transformação. Desta forma, estabelecemos um diálogo entre as proposições de Vigotski (1991, 2010) e Bakhtin (2011, 2017, 2019) às ideias de Paulo Freire $(1976,1987,1996)$. Afinal, para este, o "inacabamento do ser ou a sua inconclusão é próprio da experiência vital. Onde há vida, há inacabamento. 
Mas só entre mulheres e homens o inacabamento se tornou consciente" (FREIRE, 1996, p. 50).

Tal consciência do inacabamento leva homens e mulheres a buscar, por meio das vivências, um contato com o histórico-cultural, sendo que tal interação entre os indivíduos e o mundo se dá através da prática dialogal. Para Freire (1996), o ato de fazer e de refazer o mundo se dá a partir da inserção do homem na história, quando este se torna sujeito. Modificar as condições da existência é uma marca atribuída ao homem, tendo como resultado o desenvolvimento de um ser dialógico e crítico, forjando, assim, o espírito e a inteligência.

Neste sentido, segundo Freire (1976), o indivíduo, ao ter consciência de sua temporalidade, ou seja, de sua finitude, passa a se libertar da unidimensionalidade e, com isso, percebe que participa da historicidade. Por isso, a importância de se fugir de uma historicidade mecânica, pois esta impede o desenvolvimento de ações concretas. A história deve se mostrar como possibilidade, no sentido de possibilitar mudanças no presente.

Assim, todo conhecimento se mostra como inacabado, ou seja, deriva de um processo que se desenvolve ad continuum. Nesse sentido, a escola acaba por se mostrar como um espaço privilegiado de desenvolvimento da percepção humana, ou seja, como um ambiente próprio à aprendizagem. Para Freire $(1976,1996)$, a relação entre o professor e o aluno deve ser permeada pelo diálogo e pela ética, pelo afeto e pela estética. Tais premissas levam a uma prática que visa à libertação, por se tratar de uma educação problematizadora, ou seja, que proporciona a reflexão crítica da realidade.

Freire (1987) enfatiza a importância do diálogo como fenômeno humano que está centrado na palavra. Assim, a prática dialogal proporciona o debate, o embate, o contato com a experiência sócio-histórica.

O diálogo é este encontro dos homens, mediatizados pelo mundo, para pronunciá-lo, não se esgotando, portanto, na relação eu-tu (...) Se é dizendo a palavra com que "pronunciando" o mundo, os homens o transformam, o diálogo se impõe como caminho pelo qual os homens ganham significação enquanto homens. Por isso o diálogo é uma exigência existencial. (FREIRE, 1987, p. 78)

Destarte, é justamente na relação eu-tu, que se revela o outro como princípio constitutivo da identidade. Ademais, "a rigor, é sempre o outro enquanto eu que me 
constitui como eu na medida em que eu, como tu do outro, o constituo como eu" (FREIRE, 1997, p. 65 - grifos do autor). Ou ainda, "é a 'outredade' do 'não eu', ou do tu, que me faz assumir a radicalidade do meu eu" (FREIRE, 1996, p. 41 - grifos do autor).

Ora, temos com isso que o eu só existe por reconhecer a presença do outro. $\mathrm{O}$ indivíduo se torna alienado quando não assume a sua responsabilidade diante do outro. Ao tomar o outro como uma condição inalienável à sua própria constituição, assume-se uma responsabilidade diante da vida, no sentido de agir em busca de sua liberdade, praticando o seu poder de decisão, de avaliação ou de extrusão. Por isso, o diálogo assume uma grande importância na teoria freireana, pois centra-se no respeito a sua base.

Quando se negligencia o diálogo, anula-se a curiosidade, fator indispensável para a emancipação de si como sujeito transformador. Por isso, uma prática educativa reduzida à pura técnica, não garante o despertar da consciência como fruto de uma existência histórica.

Assim, a investigação a partir das narrativas, aliada aos pressupostos de Vigotski, Bakhtin e Freire, permite antever a maneira como o indivíduo constrói as significações sobre si e sobre o outro, possibilitando a ressignificação das vivências, de sua formação e atuação docente. Portanto, pensando nisso, é que na próxima seção apresentamos os procedimentos metodológicos que utilizamos para a produção dos dados referentes a essa pesquisa.

\section{A entrevista narrativa como instrumento de produção de dados}

Realizamos como produção de dados, quatro entrevistas com professores do Instituto Federal de Educação, Ciência e Tecnologia de São Paulo². Neste artigo, porém, trazemos para a análise a voz de um dos depoentes. Trata-se da narrativa de uma professora da instituição que ministra aulas de Língua Portuguesa e Inglês, tanto para a Educação Básica quanto para o Ensino Superior. Como forma de preservar a identidade da professora entrevistada, adotou-se o pseudônimo Cecília, em homenagem a Cecília Benevides de Carvalho Meireles, poetisa, jornalista, pintora, escritora e professora brasileira. Ao utilizar como instrumento a narrativa, notamos a possibilidade de olhar como

\footnotetext{
${ }^{2}$ Não mencionaremos o campus para preservar a identidade da professora.
}

Eutomia, Recife, 27(1): 143-163, Out. 2020 
Cecília foi se constituindo como professora-pesquisadora, bem como nos revela, a partir de alguns indícios, movimentos de seu desenvolvimento profissional.

Os encontros foram agendados e as entrevistas gravadas no âmbito do Instituto Federal. A sala escolhida foi o Laboratório de Línguas, por ser um espaço compartilhado entre os professores, o que garantiu mais segurança e confiança na hora de expor suas histórias de vida. Não houve interrupções, ou seja, a entrevista iniciou e terminou sem a interferência de nenhum outro servidor do campus, o que colaborou para garantir a singularidade das narrativas.

Em relação à entrevista da professora Cecília, esta iniciou com uma pergunta ampla, que serviu de mote ao início da construção narrativa: "Conte-me sobre a sua trajetória escolar, desde os estudos iniciais". Neste caso, a narrativa assumiu plena autonomia, deslocando-se no cronotopo e desfilando os fios da vida sem maiores perguntas. A entrevista foi realizada no dia 25 de junho de 2019, tendo a duração de 50 minutos e 23 segundos.

Em seguida, as entrevistas foram minuciosamente transcritas ${ }^{3}$, respeitando as marcações linguísticas e entoações, como forma de valorar e ressignificar as palavras, tornando-as autênticas e erigidas numa cadeia enunciativa irrepetível, trazendo legitimidade e segurança como dados de pesquisa qualitativa.

A transcrição foi enviada à professora por e-mail, em arquivo digital, para que fosse apreciada e sugeridas possiveis alterações, que poderiam ser de qualquer ordem: desde apagar algum pronunciamento, até transcrever novas informações. Todas as autorizações estão registradas e arquivadas, inclusive o "Termo de consentimento livre e esclarecido", devidamente assinado e com suas formalidades cumpridas ${ }^{4}$.

Notamos que as falas da entrevistada nos possibilitaram compreender como esta professora foi se (trans)formando, tornando-se uma professora-pesquisadora a partir das interações que foi estabelecendo com os outros, bem como traz indícios de seu desenvolvimento profissional.

\section{O desenvolvimento humano e profissional no âmbito da educação: a docência como reveladora do ato ético}

\footnotetext{
${ }^{3}$ A transcrição foi realizada pelo autor do texto de forma manual, sem a utilização de nenhum software.

${ }^{4}$ Número do Processo na Plataforma Brasil: CAAE 90778118.8.0000.5514.
}

Eutomia, Recife, 27(1): 143-163, Out. 2020 
Conforme mencionamos anteriormente, a narrativa da professora nos possibilita compreender suas (trans)formações e indícios de seu desenvolvimento profissional. Todavia, isso só se torna possível se olhamos para os enunciados considerando as contribuições de Vigotski e Bakhtin sobre o papel do outro e as interações sociais mediadas por signos e dinâmicas interativas. Vale ressaltar que, a partir das perspectivas teóricas que assumimos - a tríade Vigotski, Bakhtin e Freire - a aprendizagem e desenvolvimento são processos indissociáveis, o que implica considerar as vivências e as significações produzidas nas relações.

Assim, de forma não muito comum, os primeiros anos escolares da professora Cecília, iniciaram com a presença de sua mãe como professora, o que, em um primeiro momento, marcou sua percepção sobre a escola e sobre a sua atuação como aluna. Dessa forma, como veremos mais à frente em seu relato, tal proximidade teve um papel decisivo em sua compreensão sobre a escola e sobre a profissão docente.

Começa como aluna, aos 6 anos, na pré-escola. Eu me vejo, de repente, aluna da minha mãe, que é professora desse colégio público, dessa cidadezinha pequeninha que é Arceburgo, e eu sempre muito comunicativa, desde sempre, querendo participar de todos os eventos da Escola naquela época, e por ser filha da professora eu não tenho o direito de participar de todos os eventos comunicativos; então foi uma alegria ter minha a mãe com professora, mas ao mesmo tempo, foi, foram momentos de bloqueio, né; porque é a filha da professora, ela tirou nota porque é a filha da professora, ela não pode apresentar o recital porque é a filha da professora; então marcou muito ser, entrar na vida escolar, e ser filha da professora, né? (CECÍLIA, EN, 25/07/2019-grifos nossos).

O fato de ter a mãe como professora afetou a sua rotina, deixando marcas em seu comportamento como aluna. Sempre se mostrou propensa às atividades escolares, ao protagonismo como estudante, contudo, por conta deste bloqueio, precisou refrear suas participações e ações, bem como justificar seu saber, que deveria ir além das notas escolares, já que, ao olhar dos outros, suas notas poderiam ser oriundas do protecionismo materno.

Observamos, nesse sentido, que conforme expõe Vigotski (2007), uma atividade externa é sempre reconstruída e começa a ocorrer internamente. Essa atividade se dá, 
portanto, primeiro no nível social, e, depois, no nível individual, isto é, primeiro, entre pessoas (interpsicológica), e, depois, no interior (intrapsicológica).

Aprofundando-nos temporalmente no relato de Cecília, percebemos que, mesmo tendo a presença da mãe como uma figura inibidora em seus anos iniciais, tal aproximação fez com que sua escolha profissional se estabelecesse sem muitas dúvidas. Tornar-se-ia professora. Em seu processo narrativo, ressignificou sua trajetória, quando narra sua entrada no curso do Magistério, concomitante ao Ensino Médio: "foi muito feliz, me vi professora nesse curso, parecia uma coisa certa me tornar professora sendo filha de professora" (CECÍLIA, EN, 25/07/2019-grifos nossos).

É justo salientar que o entrave não foi imposto pela mãe, mas pelo meio escolar, uma vez que não foi a mãe que causou tal inibição, e sim a sociedade com suas imposições e pré-conceitos. Portanto, nesse momento, a presença materna já não parecia uma limitação, mas um espelhamento positivo, frutos das relações estabelecidas com o outro, sentidos que a impulsionaram rumo ao devir. E, nesse sentido,

A vivência não só pode ser expressa exteriormente (para os outros) por meio do signo (pois é possivel expressar a vivência para os outros por meio de uma palavra, da expressão facial ou de algum outro modo), mas que a vivência, até mesmo para a própria pessoa que a sente, só existe no material sígnico. Fora desse material não existe a vivência como tal. (VOLÓCHINOV, 2018, p. 120).

$\mathrm{Na}$ narrativa de Cecília, as marcas dessas vivências vão emergindo e trazendo indícios de sua constituição e formação. Narra a depoente que assim que chegou ao $4^{\circ}$ ano do Magistério, iniciou seu percurso como docente em uma escola de Educação Infantil, como professora de Educação Física. "Como eu tava ali cumprindo o magistério, e eu tinha muita vontade de ir trabalhar já na área para ver se era isso mesmo que era o meu chamado" (CECÍLIA, EN, 25/07/2019 - grifo nosso). Assim, a possibilidade de iniciar a carreira como professora começou a se cumprir antes mesmo do término do Magistério.

A influência familiar se acercou de oficializar sua escolha para o Ensino Superior, a faculdade de Letras, por conta da Língua Inglesa, que buscava praticar toda vez que sua família hospedava um intercambista. 
Durante a minha adolescência meus pais hospedaram por volta de 14 estudantes estrangeiros em casa, e aí com essa demanda de falar inglês com eles e eu tinha que optar por uma faculdade [...] aí eu optei por Letras porque eu gostava muito de me comunicar com os estudantes estrangeiros (CECÍLIA, EN, 25/07/2019-grifos nossos).

Novamente, o outro é fundamental para direcionar as escolhas de Cecília. A profissionalização daquilo que surgiu na adolescência, durante a interação com os alunos estrangeiros, passou a dirigir sua rotina pessoal e profissional, pois se tornou mantenedora de uma escola de idiomas. Consoante a isso, o casamento e a consequente maternidade, levou-a a ter menos tempo para gerir a escola como gostaria. O fato de ter dois filhos comprometeu sobremaneira a sua atuação, além do fato de a escola estar crescendo, o que demandava mais atenção. "A escola já não podia permitir que eu ficasse na sala de aula, eu tive que me afastar pra ficar na gestão desses funcionários, e a gente chegou até 200 alunos, que atendia as empresas, e isso foi me desgastando bastante" (CECÍLIA, EN, 25/07/2019 - grifos nossos). O desgaste diante da atividade de gerenciamento da escola, a levou a um esgotamento.

O fato de estar infeliz profissionalmente, a levou na busca por uma mudança na qualidade de vida e nos afazeres. Depois de 10 anos de formada em Letras, buscou uma pós-graduação Lato Sensu, com uma Especialização em Língua Inglesa. Durante o curso conheceu a professora Maria ${ }^{5}$, que a convidou para o Mestrado.

Mas acho que ela percebeu essa sede de conhecimento, de mudança; e eu tava muito desatualizada, eu não tinha feito nem TCC na época da minha graduação não exigia nem TCC. E teve um momento no laboratório de informática, ela dava aula de Metodologia também, em que ela pediu pra gente escrever um resumo científico, e eu não sabia escrever um resumo científico; e aí ela me pressionou: como assim, você chega numa Especialização sem escrever um resumo científico; porque todos os alunos lá tinham acabado de sair da graduação, e eu não aguentei a pressão e comecei a chorar, mesmo na frente da sala toda; e aí depois ela saiu comigo, foi conversando, contei a minha história de vida pra ela, e ela me ajudou [...] Se você quer realmente mudar de vida, você quer ter mais qualidade de vida, trabalhar menos e ganhar um salário mais digno, com condições mais dignas, e ficar com a sua família, eu acho que você precisa ter um diferencial, você precisa avançar para o Mestrado (CECÍLIA, EN, 25/07/2019-grifos nossos).

\footnotetext{
${ }^{5} \mathrm{O}$ nome da professora foi omitido como forma de preservar sua identidade.
} 
Percebemos que a sua atuação como docente, que tanto lhe significou desde o início de seus estudos, tendo como referência a própria mãe, agora lhe pesava em um sentido mais profundo: buscava mais qualidade em exercer sua profissão, sendo assim, o estudo a nível de pós-graduação, conforme declaração e influência de sua professora, lhe pareceu a oportunidade de mudar sua trajetória. Desta forma, percebemos que os estudos a nível de pós-graduação sugerem uma esperada mudança na carreira docente, que muitas vezes encontra-se em quase ou completa precarização, haja vista os extensos serões para atender a muitas aulas e escolas, o salário defasado, o acúmulo de funções, o excesso de trabalho que invade os momentos de lazer.

Terminei o mestrado, e no dia da minha defesa, a professora Maria, ela convidou o professor José ${ }^{6}$ da Unesp, pra minha banca, e depois da minha defesa, nós fomos almoçar juntos e ela, de surpresa, virou e falou: olha, Cecília, agora você vai continuar seu Doutorado, você vai continuar sua vida acadêmica, você vai fazer o Doutorado com o professor José (CECÍLIA, EN, 25/07/2019-grifo nosso).

Evidenciamos, neste momento, a força da dialogicidade que demonstra a capacidade de aconselhamento do professor, determinante para que o aluno siga um percurso o qual julga necessário para o seu crescimento. A professora Maria, ao ter trilhado porventura um caminho similar, ou ter sentido a angústia pela melhoria de sua carreira, levou-a a indicar a única possibilidade que, para si, era a possível: continuar seus estudos, melhorar seu processo de conhecimento. E esse conhecimento, conforme já apontamos, pressupõe sempre a vivência que Cecília teve com os outros, uma vez que

a personalidade falante, tomada por assim dizer de dentro, é inteiramente um produto das inter-relações sociais. Seu território social não é apenas a expressão exterior, mas também a vivência interior. Consequentemente, todo o caminho entre a vivência interior (aquilo que é "expresso") e sua objetivação exterior (o "enunciado") percorre o território social (VOLÓCHINOV, 2018, p. 211).

\footnotetext{
${ }^{6}$ O nome do professor, bem como o campus da Universidade Estadual Paulista na qual atua, foram omitidos como forma de preservar sua identidade.
}

Eutomia, Recife, 27(1): 143-163, Out. 2020 
Antes mesmo de concluir o Mestrado, mas em razão dele, Cecília iniciou sua docência no Ensino Superior em uma Faculdade de Tecnologia, fato que a levou a se tornar pesquisadora.

\begin{abstract}
Foi a primeira vez em que eu fui uma professora-pesquisadora. [...] Então aí, eu consegui desenvolver projetos para comunicação empresarial e, inclusive, o meu Mestrado depois, como aconteceu quase que concomitantemente, eu entrei com um tema, [...] eu trabalhei com argumentação e retórica, como os elementos prosódicos corroboravam as técnicas argumentativas dentro do discurso de autoajuda pra empresários. Eu trabalhei com palestras motivacionais, e minha metodologia foi desenvolvida aí, e com esses projetinhos que eu tinha (CECíLIA, EN, 25/07/2019-grifo nosso).
\end{abstract}

Percebemos que a função como docente do Ensino Superior a levou a se envolver de forma mais sistematizada com a pesquisa, desenvolvendo sua curiosidade epistemológica, elencando as suas disciplinas e projetos na Faculdade para a confecção de sua dissertação de Mestrado, fato que, atrelado à prática, trouxe mais significado a sua vivência como professora-pesquisadora.

Após as primeiras vivências como professora-pesquisadora, Cecília conseguiu ser aprovada em um concurso público para o Instituto Federal de Educação, Ciência e Tecnologia de São Paulo, tomando posse em regime de dedicação exclusiva. Embora estivesse receosa por ter que mudar de cidade, assim que iniciou seus trabalhos no campus, pôde mudar sua perspectiva.

E aí, quando eu pisei aqui no Instituto Federal, nossa, foi a escola dos sonhos, assim, porque eu dei uma simples, tão simples, prum $1^{\circ}$ ano Integrado à tarde, e os alunos me agradeceram tanto, me agradeceram tanto, o olhinho deles brilhava, sabe? Brilhava... E eles vinham falar comigo, e foi uma aula muito simples, mesmo. Assim, bem desprendida de tudo. E aí eu fui tomando gosto pela escola, pela cidade. E aí minha família mudou comigo depois de 6 meses, e terminei o meu Doutorado, né (CECÍLIA, EN, 25/07/2019-grifos nossos).

Vamos notando, por meio da narrativa de Cecília, o quanto ela foi se (trans)formando desde a sua escolha pela carreira docente. E essa (trans)formação sempre foi mediada pelo outro - a mãe, a família, os alunos, os orientadores, os cursos de pósgraduação, os textos teóricos entre muitos outros. Por meio dessas relações, Cecília 
aprende e, aos poucos vai se desenvolvendo profissionalmente. Cabe esclarecer, no entanto, que de acordo com Vigotski (2007, p. 103)

Aprendizado não é desenvolvimento; entretanto, o aprendizado adequadamente organizado resulta em desenvolvimento mental e põe em movimento vários processos de desenvolvimento que, de outra forma, seriam impossiveis de acontecer. Assim, o aprendizado é um aspecto necessário e universal do processo de desenvolvimento das funções psicológicas culturalmente organizadas e especificamente humanas. (VIGOTSKI, 2007, p. 103).

Nas interações que ocorreram no Instituto Federal, Cecília se tornou uma professorapesquisadora. Ali encontrou um terreno muito fértil, conseguindo cumprir aquilo que se tornou seu objetivo, sua responsabilidade a partir da parceria com professores e alunos. Tal prática acabou por direcionar alunos para a pesquisa, desenvolvendo suas curiosidades ingênuas para uma postura mais epistêmica. $E$, nesse ínterim, há os indícios de desenvolvimento profissional que ocorrem mediante as relações dialógicas.

Nesse sentido, reconhecemos as marcas de uma postura que privilegia a dialogicidade diante da vida, no sentido de auferir ao outro a possibilidade de angariar valores às suas ações cotidianas, firmando um posicionamento mediante suas escolhas, que se definem a partir de uma postura imersa na responsabilidade, na percepção de seu inacabamento como possibilidade de transformação de si e do mundo.

O professor José, que foi o meu orientador de doutorado, eu falo que ele é um anjo na minha vida, porque, assim, ele mudou a minha vida não só acadêmica, mas profissional e pessoal; ele é a gentileza em pessoa, eu percebo que eu me tornei uma pessoa muito mais humana e acessível me espelhando nele, de tratar as pessoas com igualdade, de estar sempre disponível. [...] Ele é muito generoso, e toda vez que eu vou agradecê-lo, ele fala: pague pra frente. Eu aprendi muito isso com ele; então, toda vez que algum aluno vem me agradecer, ah, você mexeu na minha vida em algum momento, eu sempre tenho essa fala do professor José. (CECÍLIA, EN, 25/07/2019-grifos nossos).

Na voz da professora, os sentidos que emergem da prática docente afetiva, logo, transformadora, que busca levar o aluno à autonomia, a ação-reflexão, sempre pautado num diálogo ético e compromissado com o desenvolvimento, tanto pessoal quanto profissional. Assim, Maria, José, os alunos, e tantos outros são vozes que influenciaram nas 
escolhas de Cecília e a levaram a permanecer na dialogicidade, no movimento ininterrupto da construção do ser, consciente de seu inacabamento (logo, rumo ao devir), levando-a a assumir o seu papel docente com responsabilidade. A atitude ética, enquanto compartilhadora de práticas voltadas à pesquisa, se reflete de forma atenuante em seu propósito de identificação que assumira ainda na Faculdade de Tecnologia, quando iniciou sua postura como professora-pesquisadora. Assumindo a curiosidade como princípio de busca no campo profissional, passou a ajudar a todos ao seu redor.

A curiosidade, própria da experiência vital, se aprofunda e se aprimora no mundo da existência humana. Enquanto inquietação em face do não-eu, espanto ante o desconhecido, ante o mistério, desejo de conhecer, de desvelar o escondido, de procurar a explicação dos fatos, de averiguar, de investigar para constatar, que possibilita a curiosidade é motor do processo do conhecimento. Dirigida ou intencionada a um objeto a curiosidade possibilita a captação das suas notas constitutivas e a produção de sua inteligência que, sendo histórica, se acha submetida a condicionamento, quer dizer, possa variar no tempo e no espaço (FREIRE, 2000, p.103).

Ao final de seu percurso narrativo, Cecília evoca a figura de um aluno, o qual representa esse movimento ético, denotando a sua ação como professora no processo emancipatório desse e de muitos outros alunos e alunas.

Um aluno meu da graduação, [...] ele tinha um problema de dicção, ele tinha um lábio leporino, mas ele também tinha sofrido um, violência em casa, e ele tinham cortado a língua; e aí foram vários processos que aconteceram na infância dele, então ele falava muito fanho, muito pra dentro; mas ele era um menino genial, e ele tinha muita habilidade pra programar, e ele não tinha muita autoconfiança [...] E um dia na aula, eu tava comentando sobre um projeto de pesquisa que eu tinha pra trabalhar com tradução automática, e ele me procurou no fim da aula pra perguntar se eu tinha alguma vaga [...] E ele foi meu aluno de iniciação científica 2 anos [...] E eu procurei as assistentes sociais, elas conseguiram um fono pra ele [...] E aí ele começou a fazer fono, a gente se aproximou, visitou a casa dele, era de chão batido, ele não sabia comer com talher, a vó dele protegia muito ele por conta desse problema que ele teve de separação dos pais, de ser agredido. E aí, ele começou a ir pra congresso pra fora, ele começou a se inscrever, ele foi no congresso da USP sozinho, e apresentou; e as pessoas começaram a me escrever perguntando da pesquisa dele, e aí eu tive que ir lá, conversar com a vó dele, porque a vó dele não deixava ele pegar ônibus sozinho; eu falava: $O$ João ${ }^{7}$ dá conta, né? Ele tem, ele é maior de idade, tem mais de 18 anos, ele

\footnotetext{
${ }^{7}$ Ocultamos o nome do aluno como forma de preservar sua identidade.
} 
sabe se virar, ele já foi comigo em outros congressos. Então, assim, a gente se aproximou dele, eu e meu marido, a gente ensinou ele a se comportar em algumas situações, porque ele ia nos congressos, ele ficava sem saber como se comportar. Então, ele aproveitou todas as oportunidades, se lançou mesmo, não teve medo; ele, a gente ofereceu ajuda, ele foi atrás e depois eu tive a oportunidade de visitá-lo, ele me mostrou super orgulhoso que tinha comprado um computador, tinha forrado a casa dele, posto piso, a vó dele já não tava mais implicando tanto com ele. Ele chegou a prestar concursos em São Paulo; ele está trabalhando na prefeitura [...] concursado na área de TI. (CECÍLIA, EN, 25/07/2019-grifos meus).

Através da prática do diálogo contínuo e ininterrupto, Cecília vai refletindo sobre sua ação docente mediante o embate de vozes distintas que entrecruzam a sua trajetória. $\mathrm{E}$ a partir dessas vozes, busca de uma forma responsiva, através da narrativa, ressignificar suas vivências, suas ações, como uma resposta eficaz na prática social.

Toda compreensão da fala viva, do enunciado vivo é de natureza ativamente responsiva (embora o grau desse ativismo seja bastante diverso); toda compreensão é prenhe de resposta, e nessa ou naquela forma a gera obrigatoriamente: o ouvinte se torna falante. A compreensão passiva do significado do discurso ouvido é apenas um momento abstrato da compreensão ativamente responsiva real e plena (BAKHTIN, 2011, p. 271).

A narrativa de Cecília nos traz indícios de sua trajetória, de sua constituição como professora, de seus aprendizados, de seu desenvolvimento profissional, uma vez que, enquanto gênero, ela possibilita a emergência de signos. A partir dos enunciados, Cecília vai ressignificando sua vivência e evidenciando a importância das relações sociais e do processo dinâmico e mutável que é o de ser e tornar-se professor. Por fim, "só uma história de vida põe em evidência o modo como cada pessoa mobiliza seus conhecimentos, os seus valores, as suas energias, para ir dando forma à sua identidade, num diálogo com os seus contextos" (NÓVOA, 1995, p. 113).

\section{Considerações finais}

Neste artigo, buscamos compreender, a partir da trajetória pessoal e profissional de uma professora do Instituto Federal de Educação, Ciência e Tecnologia de São Paulo, as 
marcas da constituição docente, bem como compreender a importância do outro nesse processo de significação do papel docente e do contexto de formação.

Com o uso da narrativa, que leva a um processo de ressignificação da vivência, é possível tornar conscientes aspectos não percebidos do próprio fazer docente, levando a compreender como se deu o processo de busca e organização das práticas de intervenção na realidade (pensando em seu desenvolvimento profissional e atuação docente). A narrativa quando contada ao outro possibilita, portanto, esse momento de autorreflexão, uma vez que o sujeito passa a ressignificar o que vivenciou por meio da própria linguagem, dos signos, do outro. É uma forma de resposta para si e para o outro, revelando a alteridade constitutiva de seu processo de desenvolvimento profissional.

Nos embates entre a fala viva da professora Cecília e os aportes teóricos de Vigotski, Bakhtin e Freire, percebemos, a partir da narrativa, que o inacabamento se torna um princípio motriz para a ação ética rumo ao devir. E, dessa forma, o diálogo se estabelece como princípio vital para construir uma relação dialógica com o outro, assumindo-o como parte de si mesmo, mediado pela responsividade. E, conforme nossas análises demonstram, colaborando com a construção do outro, colabora-se com a construção de si mesmo e do mundo.

\section{Bibliografia Citada}

BAKHTIN, Mikhail. Estética da criação verbal. 6. ed. São Paulo: Martins Fontes, 2011.

BAKHTIN, Mikhail. O Homem ao Espelho. Apontamentos dos anos 1940. São Carlos: Pedro e João Editores, 2019.

BAKHTIN, Mikhail. Os Gêneros do Discurso. São Paulo, SP: Editora 34, 2016.

BAKHTIN, Mikhail. Para uma filosofia do Ato Responsável. Trad. Valdemir Miotello e Carlos Alberto Faraco. São Carlos: Pedro \& João Editores, 2017.

BAKHTIN, Mikhail. Problemas da poética de Dostoiévski. Tradução Paulo Bezerra. $5^{a}$ ed. Rio de Janeiro: Forense Universitária, 2013.

FREIRE, Paulo. À sombra desta mangueira. São Paulo: Editora Olho D'água, 2001.

FREIRE, Paulo. Educação como prática da liberdade. Rio de Janeiro: Paz e Terra, 1976. 
FREIRE, Paulo. Pedagogia da autonomia. Saberes necessários à prática educativa. São Paulo: Paz e Terra, 1996.

FREIRE, Paulo. Pedagogia da indignação: cartas pedagógicas e outros escritos. São Paulo: UNESP, 2000.

FREIRE, Paulo. Pedagogia do Oprimido. Rio de Janeiro: Paz e Terra, 1987.

FREIRE, Paulo. Professora sim, tia não: cartas a quem ousa ensinar. São Paulo: Olho d'água, 1997.

HERNÁNDEZ, Fernando. Las historias de vida en el marco del giro narrativo en la investigación en Ciencias Sociales: los desafíos de poner biografías en contexto. In: Fernando Hernández, Juana María Sancho \& José Ignacio Rivas (Coords.). Historias de Vida en Educación: biografías en contexto. Barcelona: Esbrina - Recerca, Universitat de Barcelona, 2011.

NÓVOA, António. Vidas de Professores. Porto: Porto Editora, 1995.

REGO, Teresa Cristina. Vygotsky: uma perspectiva histórico-cultural da educação. Petrópolis: Vozes, 1995.

SOUZA, Elizeu Clementino de. O conhecimento de si: estágio e narrativas de formação de professores. Rio de Janeiro: DP\&A. Salvador: UNEB, 2006.

VIGOTSKI, Lev S. Obras escogidas III (Incluye problemas del desarrollo de la psique). Madrid: Visor, 1995.

VIGOTSKY, Lev S. A formação social da mente. 6. ed. São Paulo: Editora Martins Fontes, 1991.

VIGOTSKI, Lev. S. Quarta aula: a questão do meio na pedologia. Psicologia USP, São Paulo, v. 21, n. 4, jan. 1935/2010, p. 681-701.

VOLÓCHINOV, Valentin (Círculo de Bakhtin). Marxismo e filosofia da linguagem. Problemas fundamentais do método sociológico na ciência da linguagem. Tradução, notas e glossário de Sheila Grillo e Ekaterina Vólkova Américo. Ensaio introdutório de Sheila Grillo. São Paulo: Editora 34, 2018.

\footnotetext{
'André Plez: Doutorando em Educação pela Universidade São Francisco (USF). Mestre em Linguística e especialista em Literatura. Possui apoio da Coordenação de Aperfeiçoamento de Pessoal de Nível Superior Brasil (CAPES). Professor do Instituto Federal de Educação, Ciência e Tecnologia de São Paulo. E-mail: andreplez@gmail.com.

ii Milena Moretto: Doutora e mestra em Educação, é professora do programa de pós-graduação stricto-sensu em Educação da USF. Participa dos Grupos de Pesquisa ALTER-AGE da USP e Relações de ensino e trabalho docente da USF. Vice-líder do grupo ALTER-LEGE/USF. E-mail: milena.moretto@yahoo.com.br.
} 